\title{
A Tentative Study of Vocabulary Learning Anxiety in College English Learning in China
}

\author{
Xiaoxin Chen ${ }^{1}$ \\ ${ }^{1}$ College of Arts, China University of Petroleum (East China), Qingdao, China \\ Correspondence: Xiaoxin Chen, College of Arts, China University of Petroleum (East China), Qingdao, China. \\ Tel: 86-153-1501-0211. E-mail: chenchxx@163.com
}

Received: September 20, 2014 Accepted: October 21, 2014 Online Published: January 27, 2015

doi:10.5539/ijel.v5n1p104 URL: http://dx.doi.org/10.5539/ijel.v5n1p104

\begin{abstract}
This study presents the results of an empirical examination of the effect of the college English vocabulary learning anxiety and the English language class anxiety on college non-English majors' English proficiency in China. After the descriptive data analysis, the Pearson correlation, independent $T$ test and linear regression analysis of the data from two measures of anxiety, it is found: Students are fully aware of the importance of college English vocabulary teaching and learning, and demonstrate great anxiety in it; Significant and moderately high correlations are between college English vocabulary learning anxiety and other anxieties, which proves they are separate but related phenomena; College English vocabulary learning anxiety is significantly and negatively correlated with the CET-4 scores, but this correlation is lower than that between the English language class anxiety and the CET-4 scores; The college English vocabulary learning anxiety ranks in the middle in predicting the English language achievement, less significant than the total English language class anxiety and the communication apprehension but more significant than the fear of negative evaluation and the test anxiety.
\end{abstract}

Keywords: college English, vocabulary learning anxiety, English language class anxiety, correlation

\section{Introduction}

As abundant research suggests, successful foreign language learning involves numerous cognitive and affective factors, and factors such as affective variables, personality characteristics, cognitive styles, and learning strategies play an influential role in the learner's willingness and effectiveness to learn which are usually critical to the learner's language achievement and proficiency. Young (1991) maintains that

"Regardless of method, we know that learners need to adopt attitudes and strategies that pay off in terms of low anxiety, high motivation, and ultimately in the ability to convey information and communicate ideas and feelings. One of the current challenges in second and foreign language teaching is to provide students with a learner-centered, low-anxiety classroom environment." (p. 426)

As the importance of affective factors has been recognized by researchers investigating foreign language learning, foreign language anxiety, one of the affective factors is earning a great deal of attention. Therefore, issues dealing with anxiety in association with this process have been the focus of great attention both in China and other countries (Hao \& Hao, 2001; Horwitz et al., 1986; Li \& Lin, 2007; Liu, 2008; MacIntyre \& Gardner, 1991, 1994; Qiu \& Liao, 2007; Shao \& Zhang, 2008; Wang \& Wan, 2001; Xiong, 2012; Yang, 2000; Young, 1986, 1991; Yu, 1999; Zeng \& Liu, 2012).

Vocabulary learning has always been time-consuming but poorly-rewarding among foreign language learners in China and there is not doubt that learners suffer from anxiety in their foreign language vocabulary learning. Although relevant researches have indicated that there is a negative correlation between language anxiety and vocabulary learning, vocabulary learning anxiety has hardly been studied systematically as listening anxiety, communicative anxiety, reading anxiety, writing anxiety, foreign language classroom anxiety or test anxiety. Vocabulary learning anxiety can be defined as the feeling of tension and apprehension that the learners have during their foreign / second language vocabulary learning. According to the Input Hypothesis, only when learners have high motivation, self-confidence and low anxiety can they accept comprehensible input and acquire the target language, and this also applies to foreign language vocabulary learning. So a case study of vocabulary learning anxiety will be instructive in both college English teaching and learning. 


\section{Research Methods}

This study is mainly designed to explore the underlying dimensions of college English vocabulary learning anxiety and English language class anxiety, and to investigate the relationship between these two anxiety constructs as well as their associations with English language achievement.

\subsection{Subjects}

The subjects of this study are 318 non-English majors from twelve classes in the China University of Petroleum and they are from 6 different majors including both sciences and liberal arts. Of the 318 subjects, 108 (33.96\%) are freshmen, $109(34.28 \%)$ are sophomores, and 101 (31.76\%) are seniors. 209 male students account for $65.72 \%$ of the total, and 109 female students $34.28 \%$.

Non-English majors are chosen because the subjects' achievements and emotional experiences in college English learning are the chief concerns of this study. Non-English majors may have enough experiences with college English learning to talk about their feelings. In addition, owing to the large number of non-English majors who are learning college English in China and the special research interest of this study in participants' English language achievements, those non-English majors are more representative and are hence recruited as respondents.

\subsection{Instruments}

A questionnaire (the English Learning Questionnaire) is designed to investigate the background information of the subjects, the underlying structures of the college English vocabulary learning anxiety (CEVLA) and the English language classroom anxiety (ELCA) and to examine the relationship between them. It includes an English Language Classroom Anxiety Scale (ELCAS), a College English Vocabulary Learning Anxiety Scale (CEVLAS) and a background section to obtain demographic data about the subjects and to procure information relevant to English learning, such as gender, major, grade in university and achievement in CET-4. In addition, another 8 items concerning the significance, source, way and efficiency of college English vocabulary learning are also included in the questionnaire. The neutral background section is placed at the top of the questionnaire. The items of the ELCAS, the CEVLAS and the additional part are blended in order to derive more natural responses from the subjects.

\subsubsection{English Language Classroom Anxiety Scale (ELCAS)}

The Foreign Language Classroom Anxiety Scale (FLCAS), a 33-item self-report instrument, was developed based on "student self-reports, clinical experience, and a review of related instruments" (Horwitz, 1986). The ELCAS adopted in this study is operationalized by a translated and adapted version of the FLCAS which is a 5-point Likert-type inventory, with the scale ranging from "strongly agree" to "strongly disagree". This instrument is designed to examine the level of anxiety students experience in their college English classes and it has been widely applied both in foreign countries and in China. The internal consistency of the ELCAS in this study using Cronbach's alpha is $.914(\underline{n}=318)$, which is consistent with those in the previous studies $(.93$ by Horwitz in 1986; .94 by Aida in 1994; .93 by Yu in 1999; .88 by Lei in 2004), fully demonstrating the reliability of the ELCAS.

\subsubsection{College English Vocabulary Learning Anxiety Scale (CEVLAS)}

The 11-term section of the questionnaire in this study referred to as the CEVLAS is self-designed with a reference to the Writing Apprehension Test developed by Daly and Miller (1975). Like the ELCAS, the CEVLAS is also a 5-point Likert-type inventory, with the scale ranging from "strongly agree" to "strongly disagree". The internal consistency of the CEVLAS using Cronbach's alpha is $.830(\underline{n}=318)$, which is not as high as that of the ELCAS. As a newly designed anxiety scale, the reliability can be counted as acceptable, but much improvement is expected in the future studies.

\subsubsection{Measurements of Achievement}

For the purpose of examining the relationship between the subjects' anxiety and achievement in English learning, a measure of achievement is selected to serve as criterion variables in this study, that is, the scores some subjects received for their College English Test Band-4 (CET-4). As a college English test on a national scale, the scores of CET-4 are thus adopted for its objectivity and universality. But because the freshmen and sophomores among the volunteer students have not taken the CET-4, only the CET-4 scores of the seniors are recorded for analyses. Still these grades are representative.

\subsection{Data Gathering}

One pilot study was conducted prior to the formal survey to ensure the translation accuracy of the questionnaire 
to be used in the formal study. The data collection process of the formal study spanned from October to December, 2013. The Questionnaire was administered to each target class of students either by the author or by his colleagues at the university which took about 20 minutes to complete. With their consent, the participants' scores in CET-4 were recorded. The grades, together with the subjects' responses to the questionnaire, were then coded for computer input and double-checked. Thus a computer data file was created for all the coded data. After the investigation with the questionnaire, free interviews were conducted to explore information about some subjects' previous English study, contact with native English speakers outside the English classes, exposure to English language media, and conceptions about English learning. Eighty of the subjects were chosen at random for the interview and their answers were also recorded and categorized for analyses.

\subsection{Data Processing Techniques}

Data analyses of this study involve both quantitative and qualitative techniques.

\subsubsection{Quantitative Techniques}

Several statistical procedures were applied to analyze the quantitative data, using the newest SPSS Statistics 19.0 for Windows. Prior to data analyses, the subjects' responses to the English Learning Questionnaire, including the ELCAS, the CEVLAS, the background information and additional items concerning vocabulary learning were coded and scored. A Likert-type scale with five possible responses to each of the questions is used in scoring the ELCAS, the CEVLAS and the additional items. The scale ranges from 1 ("strongly disagree") to 5 ("strongly agree"). The participants' responses to the items are scored in such a way that the answer indicating the highest degree of anxiety receives five points, whereas the answer indicating the least anxiety receives one point.

The quantitative data are analyzed using the following statistical procedures: 1) Descriptive statistics, including percentages, means, and standard deviations, are used to summarize the subjects' responses to the questionnaire items as well as the background information of the sample. Descriptive statistics are also computed for the ELCA and the CEVLA total scores. 2) Comparisons between the different anxiety variables are conducted together with a principal components analysis of the ELCA. After that independent sample tests are conducted to explore the significance of these differences. 3) Pearson correlation analysis is conducted to examine the relationship between the ELCA and the CEVLA total scores and among the components extracted from principal components analysis of the ELCA. Pearson correlations are also computed to estimate the associations of the ELCA and the CEVLA with English course (CET-4) scores. 4) The role of different anxiety measures in predicting English language achievement is assessed by linear regression analyses. The ELCA total score, the CEVLA total score, and the component scores of the ELCA are examined for their ability to predict students' English course grades.

\subsubsection{Qualitative Techniques}

Questions are put forward in the interviews of eighty subjects selected at random to explore any additional feelings experienced by them about the college English classes and the college English vocabulary learning and to understand difficulties they have in responding to the ELCAS and CEVLAS items. The subjects' responses to the interview questions are also listed, categorized, and summarized. The frequency of each category is also calculated for analyses.

\section{Results and Discussion}

Preliminary analyses of the background information, comparison analyses of anxiety levels between the different anxieties together with the independent sample test of the significance of the differences, Pearson correlation analyses of the different anxieties, especially between the CEVLA and the ELCA as well as its three main components, Pearson correlation analyses and regression analyses between anxiety variables and achievement measures are conducted in this study and the findings are as follows:

\subsection{Preliminary Analyses}

Descriptive analyses of the background information of the participants as well as their responses to the ELCAS, the CEVLAS and the additional items concerning vocabulary learning show that:

When asked to rate their biggest difficulties in learning English, 43 interviewees (54\%) mentioned vocabulary learning, 21 (26\%) mentioned listening, and 13 (16\%) mentioned speaking. And still some mentioned writing, reading, or translation. 74 interviewees (93\%) admitted that they learned their English words mainly through textbooks and in classrooms, and other sources of vocabulary learning included extracurricular reading materials such as novels, stories, magazines and newspapers, English songs and movies, and also the Internet. Over 80\% of the interviewees reported to have quite strong motivation for learning speaking and listening skills while only 
a small proportion of them showed interest in reading, writing, and translation.

A higher score indicates a higher degree of anxiety students experience in their English language classes. In this study, the ELCA scores of the total sample range from 37 to 145, with a mean of 95.81 and a standard deviation of 20.82. The ELCA scores of the whole sample in this study are a little bit higher than the study using the 33-item FLCAS by Horwitz (1986), which reported a mean of 94.5 and a standard deviation of 21.4 in one sample of 108 students enrolled in introductory undergraduate foreign language classes at the university of Texas at Austin. While on the other hand, the scores are lower than Aida's (1994) study of students of Japanese at the University of Texas at Austin $(\underline{N}=96)$ which reported a mean of 96.7 and a standard deviation of 22.1. Phillips' (1990) study on 44 students of French at a private liberal arts university in Texas also yielded a higher mean score of 99.3 and a standard deviation of 24.6, and Lei Xiao's (2004) study on 67 non-English majors at college in China reported a mean of 94.5 and a standard deviation of 13.2. The studies mentioned here reported similar levels of anxiety. Table 1 reports the comparison between some different studies.

Table 1. Comparison between different studies

\begin{tabular}{cccccc}
\hline Researcher & This Study & Horwitz (1986) & Aida (1994) & Phillips(1990) & Lei Xiao(2004) \\
\hline & 318 & 108 & 96 & 44 & 67 \\
$\underline{\text { M }}$ & 95.8 & 94.5 & 96.7 & 99.3 & 94.5 \\
$\underline{\text { SD }}$ & 20.8 & 21.4 & 22.1 & 24.6 & 13.2 \\
\hline
\end{tabular}

\subsection{Descriptive Analyses of CEVLAS}

Like the ELCAS, the CEVLAS designed for this study is also a self-report instrument, scored on a five-point Likert scale. Because there are 11 items in the CEVLAS, it yields a composite score ranging from 11 to 55 . After reversing and re-coding responses to the positive-worded items, a higher score on the CEVLAS is found about vocabulary learning in college English. Table 2 presents the CEVLAS scores for the subjects divided by grade in college.

Table 2. Means, ranges, and standard deviations of CEVLAS scores divided by grade

\begin{tabular}{cccccc}
\hline Grade & $\underline{\mathrm{M}}$ & $\underline{\mathrm{N}}$ & $\underline{\mathrm{SD}}$ & Min & Max \\
\hline Freshmen & 35.1944 & 108 & 8.20583 & 13.00 & 51.00 \\
Sophomores & 37.1376 & 109 & 7.79775 & 21.00 & 54.00 \\
Seniors & 34.8119 & 101 & 6.14608 & 12.00 & 53.00 \\
Total & 35.7390 & 318 & 7.51053 & 12.00 & 54.00 \\
\hline
\end{tabular}

A higher score on the CEVLAS signifies a higher degree of anxiety about vocabulary learning in college English. In this study, the CEVLAS scores for the whole sample range from 12 to 54, with a mean of 35.74 and a standard deviation of 7.51. Because the CEVLAS was newly designed to test the subjects' vocabulary learning anxiety, an original attempt in this aspect, a direct comparison of mean scores with those of other studies in this aspect became impossible.

\subsection{Comparison Analyses between the Anxiety Scales}

Aida's (1994) study reported four components of the ELCAS: Speech Anxiety and Fear of Negative Evaluation, Fear of Failing the Class, Comfortableness in Speaking with Native Japanese, and Negative Attitudes towards the Japanese Class. While in this study the principal components are sorted out on the basis of the universal classification of anxieties which include: The Communication Apprehension (CA), The Test Anxiety (TA), and The Fear of Negative Evaluation (FNE). In addition, another eight items which cannot be specifically classified into these three components are labeled as The Fear of the English Class. Because the CEVLAS is an original attempt in this aspect, a direct comparison with other studies in this aspect becomes impossible. Besides, as a specific anxiety, the CEVLA serves more like a component of the whole English learning anxiety, so a comparison between the CEVLA, the CA, the TA and the FNE seems more meaningful. Here a comparison between the CEVLA, the ELCA, and the principal components is made to figure out which anxiety level is higher and their correlation with each other.

Table 3 presents the comparisons of means, ranges and standard deviations among the CEVLA, the ELCA and the three principal components of the ELCA (the FNE, The CA, and the TA). The subjects demonstrate the 
highest level of anxiety in the CEVLA, with a mean of 3.25 and a standard deviation of .68 , which is significantly higher than that of the ELCA. The mean of the ELCA is 2.90 with a standard deviation of .63. Among the three principal components of the ELCA, the highest level of anxiety occurs in the CA, the mean of which is $3.12(\mathrm{SD}=.68)$. What comes next is the TA, the mean of which is $2.93(\mathrm{SD}=.81)$. And the lowest mean (2.80) appears in the FNE, with a standard deviation of .76.

Table 3. Comparisons of means, ranges, and standard deviations among CEVLA, ELCA, and principal components of ELCA

\begin{tabular}{cccccc}
\hline & ELCA & CEVLA & FNE & CA & TA \\
\hline$\underline{\mathrm{M}}$ & 2.9034 & 3.2490 & 2.7976 & 3.1175 & 2.9324 \\
$\underline{\mathrm{N}}$ & 318 & 318 & 318 & 318 & 318 \\
$\underline{\mathrm{SD}}$ & .63103 & .68278 & .76086 & .67634 & .80823 \\
$\operatorname{Min}$ & 1.12 & 1.09 & 1.00 & 1.18 & 1.00 \\
$\operatorname{Max}$ & 4.39 & 4.91 & 4.88 & 4.82 & 4.83 \\
$\underline{\mathrm{R}}$ & 3.27 & 3.82 & 3.88 & 3.64 & 3.83 \\
\hline
\end{tabular}

This study reports a great difference in the means of the CEVLA, the ELCA, the FNE, the CA and the TA, with the highest reaching 3.25 while the lowest 2.80. But are the differences significant in terms of statistics? An independent samples test has been conducted to figure out the significance of these differences, especially the differences between the CEVLA and the other anxieties. T-tests for equality of means show that the value between the CEVLA and the ELCA is $11.417(\mathrm{p}=.000)$, the $\mathrm{t}$ value between the CEVLA and the FNE is 11.151 $(\mathrm{p}=.000)$, the $\mathrm{t}$ value between the CEVLA and the CA is $3.648(\mathrm{p}=.000)$ and the $\mathrm{t}$ value between the CEVLA and the TA is $9.475(\mathrm{p}=.000)$. So the differences between the mean of the CEVLA and those of other anxieties are considered to be significant because the $\mathrm{p}$ values are all .000, lower than .05 (a p value lower than .05 means a significant difference). Table 4 presents the independent samples test of the significance of differences between CEVLA and other anxieties.

Table 4. Independent samples test of the significance of differences between the CEVLA and other anxieties

\begin{tabular}{cccccc}
\hline & & ELCA & FNE & CA & TA \\
\hline CEVLA & $\mathrm{t}$ & 11.417 & 11.151 & 3.648 & 9.475 \\
& $\mathrm{Sig}$ & .000 & .000 & .000 & .000 \\
\hline
\end{tabular}

\subsection{Correlation Analyses between the Anxiety Scales}

In order to add to the discussion of the question concerning the relative independence or interdependence of the CEVLA, the ELCA and the principal components of the ELCA, Pearson correlation analyses are conducted to examine the interrelationships among the CEVLA, the overall ELCA, the FNE, the CA and the TA. Table 5 presents the correlation matrix.

Table 5. Pearson correlations among the CEVLA, the ELCA, the FNE, the CA and the TA

\begin{tabular}{ccccccc}
\hline \multirow{2}{*}{ ELCA } & & ELCA & CEVLA & FNE & CA & TA \\
& Correlation & 1 & $.665^{* *}$ & $.883^{* *}$ & $.873^{* *}$ & $.853^{* *}$ \\
& Sig. (2-tailed) & & .000 & .000 & .000 & .000 \\
\hline \multirow{2}{*}{ CEVLA } & Correlation & $.665^{* *}$ & 1 & $.504^{* *}$ & $.553^{* *}$ & $.691^{* *}$ \\
& Sig. (2-tailed) & .000 & & .000 & .000 & .000 \\
\hline \multirow{2}{*}{ FNE } & Correlation & $.883^{* *}$ & $.504^{* *}$ & 1 & $.724^{* *}$ & $.664^{* *}$ \\
& Sig. (2-tailed) & .000 & .000 & & .000 & .000 \\
\hline \multirow{2}{*}{ CA } & Correlation & $.873^{* *}$ & $.553^{* *}$ & $.724^{* *}$ & 1 & $.632^{* *}$ \\
& Sig. (2-tailed) & .000 & .000 & .000 & & .000 \\
\hline \multirow{2}{*}{ TA } & Correlation & $.853^{* *}$ & $.691^{* *}$ & $.664^{* *}$ & $.632^{* *}$ & 1 \\
& Sig. (2-tailed) & .000 & .000 & .000 & .000 & \\
\hline
\end{tabular}

$* * \mathrm{p}<.01$ two-tailed test 
As is displayed in table 5, the CEVLA has a significant and moderately high correlation $(\underline{r}=.67, p=.000)$ with the total ELCA. Significant and moderately high correlations are also found between the CEVLA and the three principal components of the ELCA, that is, with the FNE $(\underline{r}=.50)$, with the CA $(\underline{r}=.55)$ and with the TA $(\underline{r}=.69)$ respectively, and the $\mathrm{p}$ values are all .000 , lower than .01 . In contrast, more significant and higher correlations are found between the total ELCA and its three components: the $\underline{r}$ value between the ELCA and the FNE is .88 ( $p$ $=.000)$, the $\underline{\mathrm{r}}$ value between the ELCA and the CA is $.87(\mathrm{p}=.000)$, and $\underline{\mathrm{r}}$ value between the ELCA and the TA is $.85(\mathrm{p}=.000)$. The correlations among the three principal components also appear to be significant and moderately high: the $\underline{r}$ value between the FNE and the CA is .72 $(\underline{p}=.000)$, the $\underline{r}$ value between the CA and the TA is $.63(\underline{p}=.000)$ and the $\underline{r}$ value between the FNE and the TA .66 ( $p=.000)$.

Although the figures in table 5 report significant and from moderately high to high correlations among the CEVLA, the ELCA, the FNE, the CA and the TA, with the highest correlation between the ELCA and the FNE ( $\mathrm{r}$ $=.88)$, and the lowest correlation between The CEVLA and the FNE $(\underline{r}=.50)$, no significant differences can be spotted among these correlations. The moderately high correlation $(\underline{r}=.67)$ between the overall ELCA and the CEVLA suggests a noteworthy interlocking relationship between these two anxiety constructs. Although the existence of such an interlocking relationship is expected, its nature is not self-evident.

\subsection{Correlation Analyses between Anxiety and Achievement Measures}

Pearson correlation and linear regression procedures are employed to examine the comparative influence of the ELCA and the CEVLA on the English language achievement, for the purpose of bringing additional light to the nature of the ELCA and the CEVLA and addressing the research question: "How are Chinese EFL students' English language class anxiety and college English vocabulary learning anxiety related to their English language achievement?"

\subsubsection{Pearson Correlation Analyses}

The Pearson correlation procedure is first used to assess the correlations between the various anxieties and achievement measures. The following table reports the associations of the English language anxiety variables, including the ELCA, the CEVLA, the FNE, the CA and the TA with the English achievement measure, that is, the seniors' scores in CET-4, as well as the correlations with the various anxieties.

The scores in CET-4 of all the 101 seniors are recorded and recoded as Group 1 (270-424), Group 2 (425-499), Group 3 (500-549), and Group 4 (550-710) for analysis. These 101 subjects are from two majors of whom 64 boy students account for $63 \%$, and girls students (37) account for about 37\%. Table 6 presents the Pearson correlations between anxiety variables and the English achievement measures.

Table 6. Pearson correlations between anxiety variables and the English achievement measures

\begin{tabular}{cccccccc}
\hline & & Achievement & ELCA & CEVLA & FNE & CA & TA \\
\hline achievement & Correlation & 1 & $-.301^{* *}$ & $-.284^{* *}$ & $-.260^{* *}$ & $-.300^{* *}$ & $-.219^{*}$ \\
& Sig. (2-tailed) & & .002 & .004 & .009 & .002 & .028 \\
& $\mathrm{~N}$ & 101 & 101 & 101 & 101 & 101 & 101 \\
\hline
\end{tabular}

$* * \mathrm{p}<.01, * \mathrm{p}<.05 \quad$ two-tailed test

As is shown in Table 6, all of the anxiety variables, including the ELCA, the CEVLA, the FNE, the CA and the TA, are significantly and negatively correlated with the English language achievement, but the magnitude of the correlations varies. The figures show that the ELCA are most significantly and negatively correlated with the English language achievement, with a $\underline{\mathrm{r}}$ value of -.301 and a $\underline{\mathrm{p}}$ value of $.002(\underline{\mathrm{p}}<.01)$. The CA has a similar correlation with the English language achievement, with a $\underline{\mathrm{r}}$ value of -.300 and a $\mathrm{p}$ value of .002 (smaller than .01). As is anticipated, the CEVLA also has a significant and negative correlation with the English language achievement, and the $\underline{\mathrm{r}}$ value (-.284) and $\underline{\mathrm{p}}$ value (.004) can prove all this. What comes next is the correlation between the FNE and the English language achievement $(\underline{r}=-.260, \underline{p}=.009)$. What is a little bit surprising and hard to understand is that the correlation between the TA and the English language achievement comes the last. The $\underline{\mathrm{r}}$ value of -.219 and $\mathrm{p}$ value of $.028(\underline{\mathrm{p}}<.05)$ show that although the TA is significantly and negatively correlated with English language achievement, the correlation is least significant compared with the other correlations.

The above correlations indicate that as the ELCA and the CEVLA decrease, English language course scores 
increase, or vice versa. Specifically, more self-confidence in English learning skills and less anxiety about English classroom performance and vocabulary learning are associated with higher scores in English courses. In addition, students who are less apprehensive of others' evaluation of their English learning tend to achieve better in their English classes. Generally speaking, consistent with the results of numerous investigations that adopted situation-specific approaches to second language anxiety, these results support the detrimental effects of anxiety on foreign/second language achievement. These correlation results also demonstrate the different strengths of associations that the ELCA, the CEVLA, the FNE, the CA and the TA have with the English achievement. Although the correlation between the CEVLA and the English language achievement is not the most significant, it can never be ignored.

\subsubsection{Regression Analyses}

This section presents and discusses the results of regression analyses performed to provide a better understanding of the unique properties of the CEVLA, the ELCA, and the principal components of the ELCA. One-dimensional linear regression analyses are computed to examine the respective roles of the CEVLA, the ELCA, the FNE, the $\mathrm{CA}$ and the TA in predicting students' achievement in English language. Table 7 presents the one-dimensional linear regression of English achievement on the CEVLA, the ELCA, the FNE, the CA and the TA respectively.

Table 7. One-dimensional linear regression of English achievement on the CEVLA, the ELCA, the FNE, the CA and the TA respectively

\begin{tabular}{cccccc}
\hline & $\underline{\mathrm{F}}$ & $\underline{\mathrm{P}}$ & $\underline{\mathrm{R}}$ & $\underline{\mathrm{R}^{2}}$ & Adjusted $\underline{\mathrm{R}^{2}}$ \\
\hline ELCA & 9.882 & .002 & .301 & .091 & .082 \\
CA & 9.785 & .002 & .300 & .090 & .081 \\
CEVLA & 8.682 & .004 & .284 & .081 & .071 \\
FNE & 7.189 & .009 & .260 & .068 & .058 \\
TA & 4.988 & .028 & .219 & .048 & .038 \\
\hline
\end{tabular}

Using the CET-4 scores as the dependent variables and each of the various anxieties as independent variables, the analyses show the different demonstrations of anxiety among different score groups. The relatively high $\underline{F}$ values of the ELCA (9.882), the CA (9.785), the CEVLA (8.682) and the FNE (7.189) as well as their respective lower $\underline{P}$ value than .01 show the significant differences in anxieties among different score groups, while the $\underline{F}$ value of the TA is 4.988 with a $\underline{P}$ value of .028 ( $p>.01)$ which proves that there is no significant difference in their test anxiety among different score groups. All these findings are consistent with the findings derived from the Pearson correlation analysis.

The one-dimensional linear regression analysis regressing the CET-4 scores on the CEVLA, the ELCA, the FNE, the CA and the TA yield predictors of different significance: The ELCA is the most significant predictor and it accounts for $9.10 \%$ of the variance in the CET- 4 scores; the TA is the least significant predictor and it accounts for only $4.80 \%$ of the variance; accounting for $8.10 \%$ of the variance, the CEVLA ranks in the middle of all the predictors, less significant than the ELCA and the CA but more significant than the FNE and the TA.

\section{Conclusion}

As more and more researches set out to address the subtle effects of anxiety on foreign/second language learning, it will become increasingly important to parse out what kinds or which facets of foreign/second language anxiety are more responsible for observed outcomes or behaviors of interest. This study probes tentatively into the effect of the college English vocabulary learning anxiety and the English language class anxiety on college non-English majors' English proficiency in China. According to the study, students are fully aware of the importance of college English vocabulary teaching and learning, and demonstrate great anxiety in it; significant and moderately high correlations are between college English vocabulary learning anxiety and other anxieties, which proves they are separate but related phenomena; college English vocabulary learning anxiety is significantly and negatively correlated with the CET-4 scores, but this correlation is lower than that between the English language class anxiety and the CET-4 scores; the college English vocabulary learning anxiety ranks in the middle in predicting the English language achievement, less significant than the total English language class anxiety and the communication apprehension but more significant than the fear of negative evaluation and the test anxiety.

Despite its limitations, this study begins to spell out how the CEVLA is related to the ELCA and to the English language achievement. The present findings not only offer us a preliminary understanding about the CEVLA but 
also shed a new light on the nature of the ELCA, which provides a basis for further research that attempts to develop a more refined model of the CEVLA. It is hoped that as theorization of foreign/second language anxiety becomes more advanced, the sources and effects of the CEVLA will be more precisely identified, and effective techniques to reduce it can be figured out for our college English vocabulary teaching and learning.

\section{References}

Aida, Y. (1994). Examination of Horwitz, Horwitz, and Cope's construct of foreign language anxiety: the case of students of Japanese. The Modern Language Journal, 78(2), 155-168. http://dx.doi.org/10.1111/j.1540-4781.1994.tb02026.x

Daly, J., \& Miller, M. (1975). The empirical development of an instrument of writing apprehension. Research in the Teaching of English, 9(3), 242-249.

Hao, M., \& Hao, R. P. (2001). Research on the relationship between English achievement and achievement motivation as well as anxiety state: a case study. Foreign Language Teaching and Research, 33(2), 111-115.

Horwitz, E. (1986). Preliminary evidence for the reliability and validity of a foreign language anxiety scale. TESOL Quarterly, 20(3), 559-562. http://dx.doi.org/10.2307/3586302

Horwitz, E. et al. (1986). Foreign language classroom anxiety. The Modern Language Journal, 70(2), 125-132. http://dx.doi.org/10.1111/j.1540-4781.1986.tb05256.x

Lei, X. (2004). A research of undergraduates' English language class anxiety and its effect on English teaching. Foreign Languages in Fujian, 1, 46-51.

Li, J. Y., \& Lin, S. S. (2007). 30 years' research on second/foreign language learning anxiety abroad. Foreign Language Teaching Abroad, 4, 57-63.

Liu, C. H. (2008). Research on English Learning Anxiety of Undergraduate. China Ocean University Press.

MacIntyre, P. \& Gardner, R. (1991). Language anxiety: its relationship to other anxieties and to processing in native and second languages. Language Learning, 41(4), 513-534. http://dx.doi.org/10.1111/j.1467-1770.1991.tb00691.x

MacIntyre, P. \& Gardner, R. (1994). The subtle effects of language anxiety on cognitive processing in the second language. Language Learning, 44(2), 283-305. http://dx.doi.org/10.1111/j.1467-1770.1994.tb01103.x

Phillips, E. (1992). The effects of language anxiety on students' oral test performance and attitudes. The Modern Language Journal, 76(1), 14-26. http://dx.doi.org/10.1111/j.1540-4781.1992.tb02573.x

Qiu, M. M., \& Liao, F. (2007). Research on English language reading anxiety among chinese university students. Journal of Xi'an International Studies University, 15(4), 55-59.

Shao, X. G., \& Zhang, F. K. (2008). A study of college students' English learning anxiety in network and multimedia environment. Computer-Assisted Foreign Language Education in China, 3, 28-32.

Wang, Y. Q., \& Wan, Y. S. (2001). Foreign language learning anxiety and its effect on foreign language learning. Foreign Language Teaching and Research, 33(2), 122-126.

Xiong, S. C. (2012). A study of the relationship between language learning anxiety and learning strategy use of university students in the computer-based environment. Computer-Assisted Foreign Language Education in China, 6, 66-71.

Yang, J. (2000). The relationship between English learning anxiety and listening comprehension. Foreign Language Research, 1, 54-57.

Young, D. (1986). The relationship between anxiety and foreign language oral proficiency ratings. Foreign Language Annals, 19(5), 439-445. http://dx.doi.org/10.1111/j.1944-9720.1986.tb01032.x

Young, D. (1991). Creating a low-anxiety classroom environment: what does language anxiety research suggest? The Modern Language Journal, 75(4), 426-439. http://dx.doi.org/10.1111/j.1540-4781.1991.tb05378.x

Yu, X. L. (1999). A Study of the Relationship between Adults' English Class Anxiety and Listening Comprehension Achievements. Language Teaching and Linguistic Studies, 2, 132-143.

Zeng, X. S., \& Liu, Q. Y. (2012). A study of English learning anxiety of science and engineering college students under multimedia environment. Computer-Assisted Foreign Language Education in China, 5, 50-55. 


\section{Copyrights}

Copyright for this article is retained by the author(s), with first publication rights granted to the journal.

This is an open-access article distributed under the terms and conditions of the Creative Commons Attribution license (http://creativecommons.org/licenses/by/3.0/). 